\title{
Bolstering the Three Pillars of the Essential Architecture of the Massage Therapy Profession: an Interview with Glenn M. Hymel, EdD, LMT
}

\author{
Ann Blair Kennedy, LMT, BCTMB, DrPH, \\ Executive Editor, IJTMB \\ University of South Carolina School of Medicine Greenville, Greenville, SC, USA
}

As part of our interview editorial series, we bring forth a discussion with Dr. Glenn M. Hymel, the Founding Executive Editor of the International Journal of Therapeutic Massage and Bodywork. Dr. Hymel embodies the qualities set forth for the American Massage Therapy Association Dianne Polseno Lifetime Achievement Award, which he received in 2017. He has provided leadership and shown outstanding professionalism, and is a dedicated volunteer and a fervent advocate for research and education in the massage therapy profession. In this interview he discusses his massage therapy research, his interests, and his hopes for the future and the profession.

Dr. Glenn M. Hymel's story will continue even though he has already received the Dianne Polseno Lifetime Achievement Award (2017), one of the highest honors given by the American Massage Therapy Association. This award is bestowed upon those who have given of themselves through volunteerism, leadership, integrity, professionalism, and a dedication to advancing the massage therapy profession through research and education. Dr. Hymel embodies all of these qualities and is fully deserving of the award. Additionally, he is the next subject of our interview here at the Journal.

Dr. Hymel is the Founding Executive Editor of this Journal, Associate Editor of the Journal of Bodywork \& Movement Therapies, and an Editorial Board member for the Journal of Massage Science. $\mathrm{He}$ is the former Chair of the Department of Psychological Sciences and Professor Emeritus at Loyola University in New Orleans. He earned his bachelor's and master's degrees from Loyola University and his doctorate from the University of New Orleans. He has published and taught in the areas of education psychology, health psychology, complementary and integrative health care, philosophical psychology, and stress management, as well as research and statistics. Dr. Hymel has served on the Board of Trustees for the Massage Therapy Foundation and, in 2011, received their Distinguished Service Award; that same year the American Massage Therapy
Association also awarded him their Distinguished Service Award.

As part of our interview editorial series, we ask our interviewees a standard set of questions to try to help those in the profession learn more about what massage therapy researchers think and feel. The hope is to shine a light on research and tell researchers' stories in order to find meaning and give context for the massage therapy profession.

\section{PLEASE TELL US ABOUT YOUR MASSAGE THERAPY RESEARCH AND HOW YOU FEEL THAT IT HAS IMPACTED THE FIELD OF MASSAGE THERAPY.}

My interest in and focus on massage therapy research was initially introduced in the latter 1990s when I was first learned of a developmental psychologist named Dr. Tiffany Field's work at the University of Miami's Touch Research Institute. One of her publications was an article titled "Massage Research Effects" that appeared in the December 1998 issue of American Psychologist. ${ }^{(1)}$ That traditional narrative review genre of publication inspired me to reflect on the scientific potential for using research as a basis for advancing both educational and practice aspects of massage therapy. The logical sequence leading from research to education to practice struck me as rather obvious if indeed massage were to be advanced as an even more viable professional evolution encompassing both its scientific and artistic nature. As I embarked on my own massage therapy studies in the late ' $90 \mathrm{~s}$, I thought that perhaps my own contributions to our profession could be focused on massage therapy research given the several decades I have taught research methods and statistical courses in the behavioral sciences. As my own familiarity with massage research advanced/developed from the ' 90 s to where we are currently, it is quite obvious that the research process as a precursor to massage education and practice has been enhanced. Evidence among one of several contributing catalysts for the research-education-practice continuum is that of the 
triennial Massage Therapy Foundation's International Research Conferences ${ }^{(2)}$ inaugurated in 2005 to most recently in 2016.

\section{HOW DID YOU BECOME INTERESTED IN RESEARCHING MASSAGE THERAPY?}

One of my standard courses in Loyola University's Department of Psychological Sciences is titled "The Psychology of Personal Adjustment" that partially includes such topics as stress, fatigue, and chronic pain, as well as appropriate interventions for those health challenges. And in reviewing the literature on that particular course, that was the occasion of my first learning of the aforementioned massage research work by Field at the Touch Research Institute.

Upon graduating from my massage studies at the Blue Cliff School of Therapeutic Massage in the New Orleans Area, I became involved with the Massage Therapy Foundation and the American Massage Therapy Association (AMTA). The Foundation emphasized a particular focus on massage research and, accordingly, my own research and statistical backgrounds were a natural and obvious match to contributing to our profession. In 2006, my textbook titled Research Methods for Massage and Holistic Therapies ${ }^{(3)}$ appeared, and shortly thereafter the Foundation supported the development and eventual launch of this Journal in 2007. Not surprisingly, the $I J T M B$ included sections spanning Research, Education, and Practice, consistent with the original rationale of effective massage practice that is informed by literature-based education that, in turn, is rooted in viable valid and reliable research findings.

Advancing my own continuing interest in massage therapy research, I was privileged to start contributing in 2007 as an Associate Editor with the Journal of Bodywork and Movement Therapies under the guidance of its Editor-in-Chief, Dr. Leon Chaitow. Additionally, I am likewise very fortunate to work closely as an Editorial Board Member with Dr. Ross Turchaninov, Founder and Editor of the Journal of Massage Science.

\section{HOW DO YOU INTEGRATE STAKEHOLDERS (E.G., PRACTICING MASSAGE THERAPISTS, MASSAGE PATIENTS/CLIENTS) INTO YOUR RESEARCH PLANNING, IMPLEMENTATION, AND/OR DISSEMINATION?}

The broad range of possible stakeholders in the massage profession is obviously inclusive of practitioners, patients/clients, educators, researchers, professional association leaders, regulators, members of the public, and other health care providers. Accommodating such diversity when challenged by the needed research planning, implementation, and dissemination tasks is indeed daunting. Integrating such stakeholders in a meaningful way has the greatest potential when the construct translation ${ }^{(4,5)}$ can be variously interpreted as translational research, dissemination research, and/or knowledge transfer. Although occurring at different phases, the benchto-bedside-to-practice sequence-admittedly in a bidirectional nature - holds the greatest promise foronce again - effective massage practice informed by literature-based education that is rooted in viable valid and reliable research findings. And of those three pillars grounded in the massage profession, it appears that education serves as an intermediary function that makes possible the needed linkage between research and practice. At the risk of my belaboring the point, education's critical function would make possible neither research-alone nor practice-alone mindful of the oft-cited maxim that "theory without practice is empty; practice without theory is blind."(6)

\section{WHERE DO YOU SEE THE MASSAGE THERAPY PROFESSION AND/OR MASSAGE THERAPY RESEARCH IN THE NEXT 5 YEARS?}

Both the massage therapy profession and massage therapy research must occur in tandem over the next five years and indeed beyond. One essential and underlying basis for any viable profession (or discipline, for that matter) is that of a multifaceted research commitment constantly striving to advance the betterment of its members. Although alluded to previously, currently we must ensure the researcheducation-practice triad with several emphases inclusive of - yet certainly not limited to - advancing the following massage options: associate- and undergraduate-degree offerings; school curricula that expand research/statistical course offerings; medical massage CE/licensure/certificate/degreed options; biennial massage triad conferences inclusive of parallel emphases on research, education, and practice; translational/dissemination/knowledge-transfer research emphases; articulation and coordination with related manual therapy and other health care professionals and organizations; and offering in each issue of the $I J T M B$ an online CE option predicated on a current or recently-published article.

\section{WHAT ACCOMPLISHMENT ARE YOU MOST PROUD OF AND WHY?}

I am very proud and appreciative of the original group of colleagues with whom we worked in planning, developing, and inaugurating the $I J T M B$ 's very first issue in August of 2008. They were comprised of the following: Dr. Thomas W. Findley, Editor-inChief; Dr. Christopher A. Moyer, Research Section 
Editor; Dr. Paul Finch, Education Section Editor; and Dr. Karen T. Boulanger, Practice Section Editor. Additionally, we were/are also very proud of PubMed Central's (PMC) inclusion in the IJTMB's first issue ${ }^{(7)}$ in 2011 (viz., Vol 4, No. 1), indeed a major milestone in our open access publishing endeavor. PMC was also included at the time with seven additional electronic databases.

\section{HOW DO YOU MAKE DECISIONS?}

How do I make decisions? Quite honestly, with lots of really hard work, but ultimately with my praying for the gift of discernment that I'm always in dire need of-seriously!

\section{COPYRIGHT}

Published under the CreativeCommons AttributionNonCommercial-NoDerivs 3.0 License.

\section{REFERENCES}

1. Field TM. Massage therapy effects. Am Psychol. 1998;53(12): $1270-1281$.
2. Massage Therapy Foundation. International Research Conferences: Albuquerque, NM (2005); Seattle, WA (2010); Boston, MA(2013); Seattle, WA(2016). Evanston, IL: The Foundation.

3. Hymel GM. Research Methods for Massage and Holistic Therapies. St. Louis, MO: Mosby/Elsevier; 2006.

4. Hymel GM. Translational research queries, fascia research congress sequels, and beyond ... Int J Ther Massage Bodyw. 2010;3(1):1-3.

5. Gowan D, Leis A. Integrated knowledge translation in massage therapy research: Results of stakeholder consultation. Poster presented at the meeting of the American Massage Therapy Association National Convention, Sept. 2017, Pasadena, CA. Int $J$ Ther Massage Bodyw. 2017;10(4):8-12.

6. Morrison K, van der Werf G. Editorial [no title]. Edu Res Evaluat. 2012;18(5):399-401.

7. Hymel GM. PubMed Central inclusion, Quertle indexing, outbound reference linking, and editorial board succession: Encouraging developments in the IJTMB's evolution [editorial]. Int J Ther Massage Bodyw. 2011;4(1):1-2.

Corresponding author: Ann Blair Kennedy, LMT, BCTMB, DrPH, Department of Biomedical Sciences, Division of Behavioral, Social, and Population Health, University of South Carolina School of Medicine Greenville, 701 Grove Road, Greenville, SC 29605, USA

E-mail: Kenneda5@greenvillemed.sc.edu 